\title{
Creating Sustainable Universities: Organizational Pathways of Transformation
}

\author{
Le Kang ${ }^{1}$, Lei $\mathrm{Xu}^{2}$
}

\begin{abstract}
2030 Agenda for Sustainable Development including the SDGs, is being integrated into sustainability strategies, research, teaching, pedagogy, and campus practices, and to position higher education institutions as key drivers for achieving the SDGs. Without universities as the demonstration of sustainable development, individuals and social changes needed for the creation of a sustainable future for mankind will be difficult. Key aspects of conceptualization of a sustainable university and pathways of organizational transformation are identified in this paper based on a comprehensive literature review and cross case analysis. 17 world leading sustainable universities are selected from Australia, China, Canada, United Kingdom, United States and German. Data collection included in-depth interviews, reviews of documentary sources and analysis of routine data and information from offices of sustainability and websites of case universities. The cross case analysis of this paper depicts an effective, responsible and robust governance structure of world leading sustainable universities. The organizational pathways of transformation of sustainable universities have four key management elements: value, strategy, partnership, transparency.
\end{abstract}

Keywords: Sustainable Development; Sustainable University; Organizational Transformation.

\section{Introduction}

The Sustainable Development Goals (SDGs) cover a wide range of complex social, economic, and environmental challenges and addressing them will require transformations in how societies and economies function and how we interact with our planet.

Higher education is not only an integral part of sustainable development, but also a key enabler for it. Universities, with their social functions of creation and dissemination of knowledge and their unique position within society, have a critical role to play in the achievement of the SDGs. The United Nations' Transforming Our World: The 2030 Agenda for Sustainable Development, including the SDGs, is being integrating into sustainability strategies, research, teaching, pedagogy, and campus practices, and to position higher education as key drivers for achieving the SDGs.

The Higher Education Sustainability Initiative was created as a partnership of United Nations entities in the run-up to the Rio+20 Conference, as a way for HEIs to show their commitment towards comprehensively integrating sustainable development practices into their core mission. Numbers of HEIs has responded and showed good progress in implementation of SD and SDGs, fostering sustainability literacy of students; taking interdisciplinary research beyond the campus to engage with communities on SDrelated issues: climate change, energy consumption, food security, extreme weather 
events, ecosystem adaptation, human health and more. They are not only models of sustainable organizations, but also serve as living laboratories for new SD ideas, demonstrating to others how to create a more sustainable future. These HEIs are known as sustainable universities.

The quite dramatic environmental changes and reforms affected a number of higher education systems providing an important backdrop to the focus on creating sustainable universities. Engaging with the SDGs will benefit universities by helping them demonstrate social impact, capture demand for SD-related education and research, build new partnerships and define a university that is more responsible and globally aware. But due to the silos between the SDGs and academic goals of universities and scholars, many universities are still not being motivated at a global scale.

\section{Literature Review}

During the past two decades (2000-2018), 23 papers relevant to the theme of "sustainable university" (SU) were published in the following leading international journals: Journal of Cleaner Production, International Journal of Sustainability in Higher Education, Higher Education Policy, Higher Education, Journal of Education for Sustainable Development, etc. The authors collected and analyzed definitions and elements descriptions of SU from these literatures. See Appendix 1.

According to research questions, literature review is elaborated as the following three aspects:

\subsection{The Concept of the Sustainable University}

From the perspective of triple bottom line theory, Rebeka Lukman and Peter Glavic (2007) revealed the concept of the sustainable university should comprise all three realms of sustainable development: environmental protection, economic performance, and social cohesion. Luis Velazquez (2006) defines the sustainable university as " a higher educational institution, as a whole or as a part, that addresses, involves and promotes, on a regional or a global level, the minimization of negative environmental, economic, societal, and health effects generated in the use of their resources in order to fulfill its functions of teaching, research, outreach and partnership, and stewardship in ways to help society make the transition to sustainable lifestyles".

Although there is no uniform formalization definition of sustainable university, scholars are generally aware of the duality of the concept, including achieving sustainability of university and leading sustainable development of the society. While, only few articles disclosed the differences between the traditional university and the sustainable university.

\subsection{Key Elements of Sustainable Universities}

The intentionally generic understanding of a sustainable university has been elaborated more explicitly as key elements. A growing consensus has emerged on some of the elements that constitute a sustainable university.

Rodrigo Lozano (2006) identifies five dimensions for sustainable universities including education and research on sustainability, university operations, external community, assessment and reporting. These dimensions are considered interconnected and hence 
treated as comprehensive, and crucial for the holistic implementing of SD.

Rodrigo Lozano (2015) and his research team acknowledge that the HEIs system is comprised of several inter-related elements; commit to sustainability by integrating it into policies and strategies; show the commitment by signing a declaration, charter or initiative; establish short-, medium-, and long-term plans for its institutionalization; and ensure that sustainable development is implemented throughout the system.

A shift occurred in the understanding of sustainable universities, from "green campus" covering waste management, recycling, and saving natural resources - to implementation of SD values and principles in education (referring to curriculum and teaching), research, operation and community outreach. Key elements from Literatures are depicted in Figure 1.

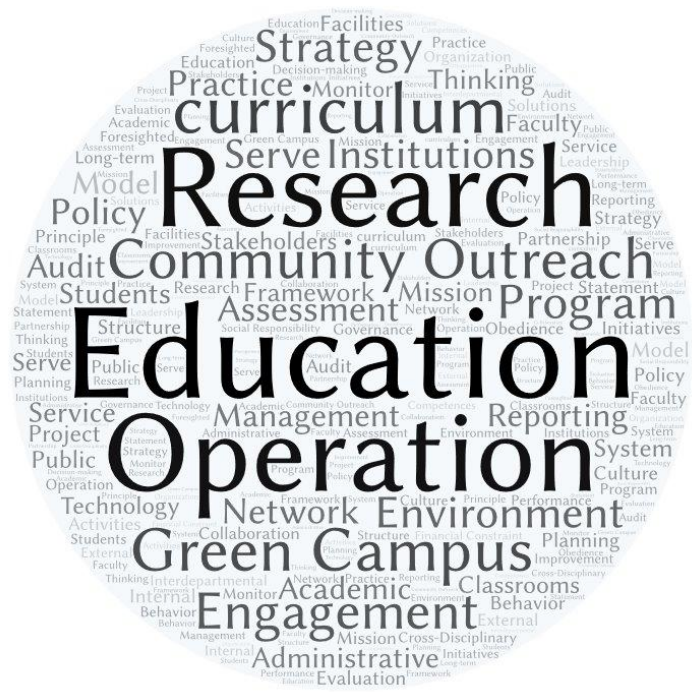

Figure 1: Key elements of sustainable universities

Sustainability is defined as meeting the needs of present without limiting the ability of fulfilling the needs of future generations. Sustainability is a complex, multidimensional and dynamic concept, consequently, key elements of sustainable universities are difficult to be identified. There are still some elements with less attention like non-materialistic aspect of sustainability related to administration, culture and ethics.

\subsection{Sustainability Framework for HEIs}

Creating sustainable universities need to break down structural constraints of the prevailing unsustainable systems of traditional HEIs. Hence, the core research topic is organization transformation. A number of sustainable university models have been proposed as a way to develop universities' vision, mission, strategies and approaches. They are usually followed by assessment, monitoring, reporting techniques and a number of proposed indicators (Fischer et al, 2015).

Hans van Weenen (2000) proposed the sustainable university classification model which meant to classify university involvement in SD as a general framework for assessing 
university status or progress. An empirical review examined the factors that influence the adoption of sustainable practices. Results show that size and wealth are significant factors in the adoption of sustainable practices and stakeholders such as faculty, alumni, and the surrounding community also play an important role (2011). Fikret Korhan Turan, Saadet Cetinkaya et al.(2016) propose a framework that can be used in higher education institutions for integrating stakeholders preferences into strategic decisions. Their research shows stakeholders' highest priority is teaching, followed closely by research.

Taya Louise Owens (2017) defined the core forms of higher education sustainable development initiatives: academic, operational and administrative. The structure of the sustainable university should also include: networking with other universities; sustainability audits to monitor, analysis and controlling the performance of sustainable initiatives; and obedience to the continuous improvement principle (Amaral et al, 2015).

\section{Research Framework}

The results of a university's past and present decisions and activities positively or negatively affect the economy, environment, or society whether in whole or in part. Social responsibility becomes an obligation for long term operations of the universities, in other words for sustainability. Universities that want to be socially responsible must integrate social, environmental, and economic considerations in their core activities.

Triple Bottom Line (TBL) social responsibility construct is a transparent and defensible model for enhances sustainable development of organizations. TBL is anchored by three elements - economic, environmental, and social - all three find a compelling nexus in the social responsibility construct. TBL, also known as people, planet and profit, is gaining support especially among large organizations - irrespective of whether or not they are global or local in nature - because it captures an expanded worldview that goes beyond just profit (McWilliams et al, 2016).

Elkington (1999) advocated seven revolutions that must take place in order for TBL to be in sync with the traditional financial bottom line: corporate governance, partnership, markets, values, life-cycle technology, transparency, and time. Figure 2 shows an overview of the three integrated components of TBL.

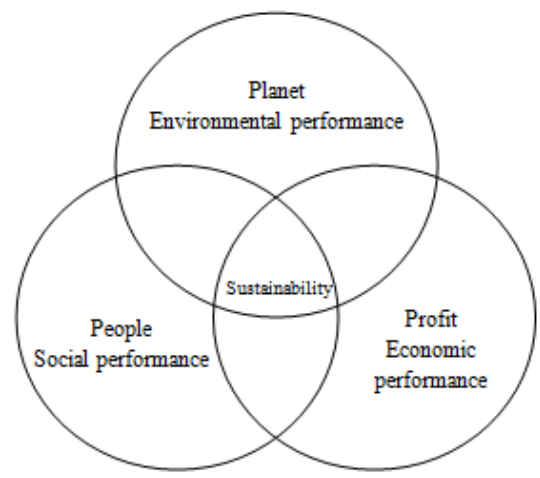

Figure 2: Triple bottom line theory 
At the perspective of TBL, the sustainable university can be defined as adapting economic, environmental and social factors into organization operations as well as management principles and managing potential risks in order to create value to sustainable development. Transforming sustainable university is driven by the pursuit to maximize a university's contribution to sustainable development.

In the Triple Bottom Line approach, economic sustainability takes the view that the university should operate in a low-risk financial situation to maintain its reasonable budget, quantity and quality of faculty and students, efficient and fair distribution and consume of resources while achieving academic and educational goals, etc.

Controlling Environmental bottom line means managing, monitoring, and reporting the consumption and waste and emissions of the university, protection of the environment, biodiversity and restoration of natural habitats, concern with environmental sustainability of society in large.

The social bottom line regarded as maintaining and improving human capital, uphold the workforce diversity and equal opportunity, fair operating practices, health and safety, community involvement.

\section{Cross Case Study}

\subsection{Overview of Cases}

This cross-case study included 17 cases. Universities were selected for the case study series if they commit to: (a) teaching sustainable development across all disciplines of study, (b) encouraging research and dissemination of sustainable development knowledge, (c) greening campuses and supporting local sustainability efforts, (d) and engaging and sharing information with international networks.

Table 1 shows the list of universities that participated in the survey.

Table 1: Information of Cases Universities

\begin{tabular}{lcc}
\hline \hline University Name & Country & Type \\
\hline Australian National University & Australia & Public \\
University of Melbourne & Australia & Public \\
University of New South Wales & Australia & Public \\
Tsinghua University & China & Public \\
Tongji University & China & Public \\
University of Hongkong & China & Public \\
University of British Columbia & Canada & Public \\
McGill University & Canada & Public \\
University of Waterloo & Canada & Public \\
University of Edinburgh & United Kingdom & Public \\
University of Manchester & United Kingdom & Public \\
University of St Andrews & United Kingdom & Public \\
Harvard University & United States & Private \\
Stanford University & United States & Private \\
Cornell University & United States & Private \\
Leuphana University of Lüneburg & German & Public \\
University of Tübingen & German & Public \\
\hline
\end{tabular}


As an example of Chinese sustainable university, Tsinghua University has committed itself to building the "Green University" since 1998, by integrating SD into teaching, research and campus construction, and building a sustainable university.

270 courses related to sustainability education have been set up in Tsinghua University, involving more than 20 departments and across all disciplines, and accepted by tens of thousands of colleges students.

Institute for Sustainable Development Goals of Tsinghua University was established on May 14th, 2017. This institute aims to establish a leading platform to conduct interdisciplinary research on sustainable development and collaborate with global partners to address challenges in implementing UN SDGs. Tsinghua University and the Massachusetts Institute of Technology are working together on the China Energy and Climate Project to study policy in China and improve the management of climate change. Tsinghua University advocated a range of activities on eco-friendly transport, carbon emission reduction, monitor platform construction of campus energy, waste management, campus landscape to construct green campus. Tsinghua University started micro-cycle electric vehicle system in 2016, and 30 smart electric vehicles created 3 routes on campus for teachers and students. This was the first pure electrics systems conducted in Chinese universities on the scale. Faculties and students of Tsinghua could download the smart bus application adopted Internet of Things technology.

\subsection{Data Collection}

17 sustainable universities are selected from six countries. Data collection included in-depth interviews, reviews of documentary sources (sustainability strategic plan, annual reports of sustainability, environmental management plan) and analysis of routine data and information from offices of sustainability and Green Campus website of case universities.

The cross-case analysis was conducted by the first author, who had led two co-authors of the original case studies in China and Canada. Two co-authors provided original case studies in Australia, US, UK and German.

15 participants of in-depth interviews are administrators, staff, faculty and M.A. students from the office of sustainability, school for sustainability, Institute for Sustainable Development of case universities in China, German, UK and US. So far, the authors didn't have the chance to implement in-depth interviews in Canada and Australia, and this is a research limitation of this paper.

Participants were chosen because: administrators and staff have participated in sustainability initiatives implemented in universities; faculty and M.A. students are working to research and implement sustainability. All the participants contribute to organizational transformation as a member of the university community.

A qualitative, descriptive, cross case analysis of organizational elements of sustainable university was conducted after the 17 case studies had been completed.

\subsection{Results}

17 sample universities all express sustainability dimensions in values (vision, mission statements, and principles). The SD values and principles also have been repeatedly emphasized by top-level managers of sample universities. For example, in 
former president of Stanford University John Hennessy's vision that sustainability will "become a core value in everything we do." Pei Gang, the president of Tongji University believed that "To run a university is to lead the trend of sustainable development." Peter Salovey, President of Yale University, shares his thoughts that universities, born with social responsibilities, take sustainability as the core of education and research.

17 sample universities have defined ways of conceptualizing a sustainable university in strategies, plans, policies. The typical formal documents include: 20 Year Sustainability Strategy for the University of British Columbia, Vision 2020- McGill's Sustainability Strategy, The University of Edinburgh Social Responsibility and Sustainability Strategy 2010-2020, Stanford University Sustainability 3.0 Strategic Plan, The Australian National University Strategic Plan 2017-2021, etc.

Not just in university-level partnership for SD, 17 sustainable universities enhance the cooperation with other countries in the implementation of 2030 Agenda for Sustainable Development. These sustainable universities all engage and share SD knowledge, forecasting techniques and information of SD and SDGs with international networks, in order to address global issues that were beyond the purview of one sector-be it public, private, or nongovernmental agencies.

In the absence of mandatory reporting requirements and reporting guidelines specific to universities, universities can tailor an approach that suits their own values, priorities and existing reporting activities. On the element of transparency, 13 case universities released annul sustainability report (or social responsibility and sustainability report of UK universities), in addition, University of Manchester released social and economic impact report 2016/2017. Tsinghua University, Tongji University, Leuphana University of Lüneburg and University of Tübingen have not released a sustainability report yet. The researchers couldn't access to monitor \& assessment results of sustainability indicators of these four universities.

Table 2: Key Management Elements of Cases Universities

\begin{tabular}{lcccc}
\hline \hline University & Values & Strategy & Partnership & Transparency \\
\hline ANU & $\bullet$ & $\bullet$ & $\bullet$ & $\bullet$ \\
U. Melbourne & $\bullet$ & $\bullet$ & $\bullet$ & $\bullet$ \\
UNSW & $\bullet$ & $\bullet$ & $\bullet$ & $\bullet$ \\
Tsinghua U. & $\bullet$ & $\bullet$ & $\bullet$ & $\times$ \\
Tongji U. & $\bullet$ & $\bullet$ & $\bullet$ & $\times$ \\
HKU & $\bullet$ & $\bullet$ & $\bullet$ & $\bullet$ \\
UBC & $\bullet$ & $\bullet$ & $\bullet$ & $\bullet$ \\
McGill & $\bullet$ & $\bullet$ & $\bullet$ & $\bullet$ \\
Waterloo & $\bullet$ & $\bullet$ & $\bullet$ & $\bullet$ \\
Edinburgh & $\bullet$ & $\bullet$ & $\bullet$ & $\bullet$ \\
Manchester & $\bullet$ & $\bullet$ & $\bullet$ & $\bullet$ \\
St Andrews & $\bullet$ & $\bullet$ & $\bullet$ & $\bullet$ \\
Harvard U. & $\bullet$ & $\bullet$ & $\bullet$ & $\bullet$ \\
Stanford U. & $\bullet$ & $\bullet$ & $\bullet$ & $\bullet$ \\
Cornell U. & $\bullet$ & $\bullet$ & $\bullet$ & $\times$ \\
U. Lüneburg & $\bullet$ & $\bullet$ & $\bullet$ & $\times$ \\
U. Tübingen. & $\bullet$ & $\bullet$ & $\bullet$ & $\bullet$ \\
\hline
\end{tabular}


The respondents of Tsinghua University and Tongji University explained there were no policies, ordinances and statutes for Chinese universities to assessment and reporting university sustainability. Tsinghua University plans to cooperate with a technology company to monitor the carbon footprint and other environmental indicators of campus in the near future. Leuphana University of Lüneburg and University of Tübingen have undertaken to enlist education, research and knowledge transfer to contribute to sustainable development. The respondents of Leuphana University of Lüneburg introduced some data was provided in the university website of sustainable development and official news. The main obstacle for Chinese and Germany case universities' disclosure sustainability performance information is lacking of institutional support.

\section{Research Findings}

The cross-case study indicates world leading sustainable universities have an effective, responsible, inclusive and robust governance structure and management systems to meet the needs of sustainable development, and to promote and lead the sustainable development of society.

The governance structure and management systems include four common elements: values, strategy, partnership, transparency. These governance elements affect the achievements of sustainable universities. Furthermore, based on research findings, this research explored logical steps for universities willing to transit to sustainable university in a responsible way.

\subsection{Sustainable Development Values}

The concept of sustainability calls for long-term future orientation and envisioning. Universities should integrate SD values into organization operation and culture, so as to let SD values lead all the teaching, leaning, research and management activities.

\subsection{Sustainability Strategy}

Sustainability should be an integral part of a university's strategy, which is the most critical step to organization transit. Successful sustainability strategies are flexible, resilient, and responsive. Similarly, the principles and practices developed for sustainability organizational transformation should have a flexible, adaptable character to ensure their relevance in a variety of different settings (Erin Frisk et al, 2011).

\subsection{Building Successful Partnerships}

Universities and stakeholders need to break down silos and build teams to promote the SD transformation. The term partnerships is used here, rather than the more common public-private partnership, to represent their status accurately as social problem-solving mechanisms among organizations and individuals.

Rethinking the governance structure of a university is a challenging task. Without the participation of stakeholders, the transformation of a university would not happen. Overcoming barriers of transformation processes towards sustainability requires collaboration across stakeholders. The perspectives and experiences of varying 
stakeholders are also critical for providing local knowledge and information about the values and concerns that inform societal actions.

\subsection{Transparency of SD Governance}

Universities need better available data on sustainability performance to affect policymakers and other stakeholders. There is an emerging consensus that release a sustainability report is related to the strategic commitment of the university to sustainability, its organizational capabilities to produce these reports, and the level of its sustainability performance. The Global Reporting Initiative Guidelines is a very competent set of indicators to assess sustainability performance. The STARS inventory provides a similar checklist to the GRI.3 standards but specifically geared to universities.

\section{Conclusion}

Modern social organizations need to transform to respond to the changes in their operating environment. Many scholars, practitioners and policymakers are relying on universities to lead the world towards sustainability. Universities have been identified as key drivers in helping to make the transition to a sustainable society and this demonstration of sustainability initiatives.

However, a number of universities are still lagging behind to contributing sustainable development. Current efforts of universities are inadequate for achieving transformative action. Creating Sustainable Universities is not an event but a process. The larger goals of shifting the values, organization operation, transparency and partnership actions of all HEIs worldwide demand a long-term societal effort.

\section{References}

Lukman, R., Glavic, P. (2007). What are the key elements of a sustainable university?. Clean Technologies and Environmental Policy, vol.9, no.2, pp.103-114.

Velazquez, L., Munguia, N., Platt, A., Taddei, J.(2006). Sustainable university: What can be the matter? Journal of Cleaner Production, 14(9-11), pp. 810-819.

Lozano, R.(2006). Incorporation and institutionalization of SD into universities: breaking through barriers to change, Journal of Cleaner Production, 14(9-11), pp.787-796.

Lozano, R., Ceulemans, K., Alonso-Almeida, M., Huisingh, D., et al.(2015). A review of commitment and implementation of sustainable development in higher education: results from a worldwide survey, Journal of Cleaner Production, vol. 108, pp.1-18.

Daniel Fischer, Silke Jenssenb, Valentin Tappeserc (2015)., Getting an empirical hold of the sustainable university: a comparative analysis of evaluation frameworks across 12 contemporary sustainability assessment tools, Assessment \& Evaluation in Higher Education, vol. 40, no. 6, pp.785-800.

Hans van Weenen (2000). Towards a vision of a sustainable university, International Journal of Sustainability in Higher Education, vol.1, no.1, pp20-34.

Fikret Korhan Turan, Saadet Cetinkaya, Ceyda Ustun (2016). A methodological framework to analyze stakeholder preferences and propose strategic pathways for a sustainable university. Higher Education, vol.72, pp.743-760.

Sarah L. Stafford (2011), How green is your campus? an analysis of the factors that drive universities to embrace sustainability, Contemporary Economic Policy, vol.29, no.3, pp. 337-356.

Taya Louise Owens (2017). Higher education in the sustainable development goals framework. European Journal of Education, vol.52, no.4, pp. 414-420. 
Amaral,L. Martins N., Joaquim B. Gouveia (2015). Quest for a sustainable university: A review, International Journal of Sustainability in Higher Education, vol.16, no.2, pp.155-172.

McWilliams,A., Parhankangas,A., Coupet, J. Welch E.(2016). Strategic decision making for the triple bottom line. Business Strategy and the Environment, vol.25, pp.193-204.

Elkington,J.(1999). Cannibals with forks: The triple bottom line of 21 st century business. Gabriola Island, Canada: New Society, pp. 127-129.

Erin Frisk, Kelli L. Larson (2011). Educating for sustainability: Competencies \& Practices for Transformative Action. Journal of Sustainability Education, vol. 2, pp.17-34. 